\title{
Significance of irregular opacities in the radiology of coalworkers' pneumoconiosis
}

\author{
J. P. LYONS, R. C. RYDER, H. CAMPBELL, W. G. CLARKE, and \\ J. GOUGH \\ Pneumoconiosis Medical Panel, Cardiff and University Departments of Pathology and \\ Medical Statistics, Welsh National School of Medicine
}

Lyons, J. P., Ryder, R. C., Campbell, H., Clarke, W. G., and Gough, J. (1974). British Journal of Industrial Medicine, 31, 36-44. Significance of irregular opacities in the radiology of coalworkers' pneumoconiosis. A correlation study of ventilatory, morbid anatomical, and radiological findings in 95 deceased coal miners who suffered with simple pneumoconiosis during life was undertaken using the new ILO U/C International Classification of Radiographs of Pneumoconiosis, which now provides for the occurrence of irregular opacities in addition to the classical rounded opacities. The study was carried out with a view to ascertaining the frequency of occurrence and the significance of irregular opacities in coalworkers' pneumoconiosis. Two $x$-ray films with an average interval of 11 years between them were reported on'in each case. The results showed that irregular opacities amounting to category 1 or more were present in $20 \%$ of the earlier films and in $48 \%$ of the later ones. Exceptionally they occurred alone but were usually admixed with classical rounded opacities.

Irregular opacities correlated positively with the extent of emphysema and the impairment of $\mathrm{FEV}_{1}$, whereas rounded opacities did not.

Possible pathological causes for the irregular opacities are discussed and it is maintained that coalworkers' pneumoconiosis is the most probable one. Finally, it is suggested that the significance of these irregular changes may have been underrated in certain cases hitherto, with consequent underestimation of pneumoconiosis and its related effects.

Morphological findings in a typical case showing radiologically mixed irregular and rounded opacities are demonstrated.

The new ILO U/C International Classification of Radiographs of Pneumoconiosis (Revised 1968), published by the International Labour Office, Geneva, provides for the occurrence of both rounded and irregular opacities in simple pneumoconiosis. Thus, in addition to the symbols ' $p$ ', ' $q$ ', and ' $r$ ' (formerly ' $p$ ', ' $m$ ', and ' $n$ ') representing the recognized rounded opacities, irregular opacities designated 's', 't', and ' $u$ ' are now also recognized, 's' representing fine irregular or linear opacities, ' $t$ ' representing medium, and ' $u$ ' representing coarse (blotchy) irregular opacities.

The classification has been broadened in an effort to cover a wider range of pneumoconioses, particu- larly those causing interstitial pulmonary changes such as asbestosis, in which irregular opacities are recognized to occur.

The descriptive literature (ILO, 1970) accompanying the new classification states that irregular opacities may also occur in the primarily nodular forms of pneumoconiosis such as 'silicosis, mixed dust pneumoconiosis, and occasionally in coalminers pneumoconiosis', This probably understates the case insofar as coalworkers' pneumoconiosis is concerned since irregular opacities have long been recognized and described as 'reticular', 'cobweb'. 'network', 'linear', etc., and in one of the earlier descriptions of the radiological changes in coal- 
workers' pneumoconiosis in this country, Hart and Aslett (1942) stated 'the outstanding feature is reticulation which passes on to various degrees of consolidation'.

The term 'reticulation' was used by many authors during the 1940s to describe the radiological changes in simple coalworkers' pneumoconiosis, but towards the end of that decade it was becoming apparent to pathologists and other workers that the very earliest changes were primarily rounded rather than linear. Gough (1947) stated that the $x$-ray picture consisted of small opacities which may remain discrete as separate granules or may be linked into an ill-defined network, and Gough, James, and Wentworth (1949) demonstrated, using large paper sections of the lung for the first time, the nodular nature of early simple coalworkers' pneumoconiosis. They also showed that severe focal emphysema produced a sharply defined network appearance in some of the radiographs, although often this pathological manifestation had no radiological counterpart. The classical study of Heppleston (1947) also clearly showed that the earliest morbid anatomical lesions in coalworkers' pneumoconiosis were focal areas of consolidation surrounded by emphysema. He described them as macules of blackened parenchyma, $1-4 \mathrm{~mm}$ in diameter, stating that 'the smaller lesions were rounded or oval, the larger irregular or stellate'.

Fletcher et al. (1949) devised a radiological classification which was largely based on rounded opacities, and although 'cobweb' and 'chronic bronchitic' changes are included in this, they were dropped from the version of the classification which was put forward at the International Labour Office Conference in Sydney in 1950.

This classification, which was subsequently accepted internationally, has survived with very little modification up to 1969 , and although the introduction of the symbols ' $z$ ' and ' $L$ ' in 1958 went some way towards re-introducing linear opacities, the use of terms denoting them fell largely into disuse in the descriptive radiology of coalworkers' pneumoconiosis. This was unfortunate because while it was probably true that the earliest $x$-ray changes in coalworkers' pneumoconiosis were predominantly nodular, there was no evidence to show that reticular changes might not sometimes occur or might not appear as a later rather than an earlier feature of the disease. It is our experience that these changes are frequently a late feature of the disease process although they may not always be recognized as such, and it is our purpose in this paper to examine both the frequency of occurrence and significance of irregular opacities in simple coalworkers' pneumoconiosis.

\section{Materials}

In order to determine the frequency of occurrence and also the significance of the irregular opacities in coalworkers' pneumoconiosis, we have utilized radiological, physiological, and morbid anatomical material available to us as a result of a correlation survey carried out jointly between the Pneumoconiosis Medical Panel, Cardiff and the University Departments of Pathology and Medical Statistics of the Welsh National School of Medicine on coal miners who died between 1965 and 1967. A detailed description of the miners concerned and of the methods of investigation have already been given by Ryder, Lyons, Campbell, and Gough (1970) and Lyons, Ryder, Campbell, and Gough (1972), so only very brief relevant details are given here.

In our earlier studies we reported on 247 miners who had died and had been resident in a defined area of South Wales; in the present study we re-read the $x$-rays for all those cases whose $x$-rays had been reported as showing simple pneumoconiosis only who did not have progressive massive fibrosis in those studies. There were 95 such cases; all had attended the Cardiff Pneumoconiosis Panel at least once in the four years preceding death, all had a final $x$-ray before death, and all had detailed contemporaneous pulmonary function tests, all had postmortem whole-lung sections prepared and a quantitative assessment of emphysema according to the method of Ryder, Thurlbeck, and Gough (1969). Seventy-five cases had available an $x$-ray taken at the time of first diagnosis by the Panel, on average 11.3 years earlier, 15 cases had earlier $x$-rays which were on average 11 years before the final $x$-ray, and in five cases earlier $x$-rays were not available.

\section{Method}

The 185 radiographs were read in random order by a single reader (W.G.C.) who has been intimately connected with the ILO Classifications since their inception. The ILO U/C (Extended) International Classification 1968 was used, the films being read for both rounded and irregular opacities according to the 12 point scale of this classificaton, i.e., $0 /-, 0 / 1,1 / 1,1 / 2 \ldots 3 / 4$, the ILO category into which the film fits being the first recorded, the second figure representing the nearest serious alternative category. The ILO standard films were used during the readings. The profusion of rounded and irregular opacities was recorded separately.

Because of the additional features recorded in the classification it was felt that readings of a single highly experienced reader would be at least as accurate as readings from a number of readers who were not quite so familiar with the new classification. In addition, it was felt that the accuracy obtained from a reading of this nature would be adequate for this investigation. Names and dates on the films were obscured, although it is not thought likely that knowledge of this would produce any significant biases, and the reader was in any event not at the time aware of the final purpose for which the readings were being carried out. The 95 whole-lung sections had already been examined by one of us (R.R.) and the emphysema count then recorded was used in this study.

Each miner at the time of his final $x$-ray also had an assessment of his pulmonary physiology. The forced expired volume in one second $\left(\mathrm{FEV}_{1}\right)$ was related to the expected normal values standardized for age and height, 
T A BLE 1

95 Cases of Simple Pneumoconiosis:

First X-RAY COMPared to Final X-RAY before DeATH

\begin{tabular}{|c|c|c|c|c|c|c|c|}
\hline \multicolumn{4}{|c|}{ First $x$-ray } & \multicolumn{4}{|c|}{ Final $x$-ray } \\
\hline Category & Classificat & & Total & None & Rounded & Irregular & Mixed \\
\hline \multirow[t]{2}{*}{$\begin{array}{l}0 /--0 / 1 \\
1 / 0-3 / 4 \\
1 / 0-3 / 4 \\
1 / 0-3 / 4\end{array}$} & $\begin{array}{l}\text { No opacities } \\
\text { Rounded opacities } \\
\text { Irregular opacities } \\
\text { Mixed opacities }\end{array}$ & $\begin{array}{ll}\ldots & \ldots \\
\ldots & \ldots \\
\ldots & \ldots \\
\ldots & \ldots\end{array}$ & $\begin{array}{r}17 \\
55 \\
4 \\
14\end{array}$ & $\frac{2}{11}$ & $\begin{array}{r}8 \\
26 \\
\frac{2}{2}\end{array}$ & $\begin{array}{l}3 \\
2 \\
1 \\
4\end{array}$ & $\begin{array}{r}4 \\
16 \\
\cdot 3 \\
7\end{array}$ \\
\hline & $\begin{array}{l}\text { Matched cases at fin } \\
\text { Previous } x \text {-ray films } \\
\text { All cases at final } x \text {-r }\end{array}$ & $\begin{array}{l}\text {-ray } \ldots \\
\text { available } \\
\ldots \quad \ldots\end{array}$ & $\begin{array}{r}90 \\
5 \\
95\end{array}$ & $\frac{14}{14}$ & $\begin{array}{r}36 \\
3 \\
39\end{array}$ & $\frac{10}{10}$ & $\begin{array}{r}30 \\
2 \\
32\end{array}$ \\
\hline
\end{tabular}

and the difference between the actual and expected FEV 1 was termed the deficit in $\mathrm{FEV}_{\mathbf{1}}$.

\section{Results}

For simplicity, the readings have been summarized in Table 1 into four main groups, those films showing rounded opacities only, those showing irregular opacities only, those showing mixed opacities, and those films in which the reader found no opacities; but, of course, the detailed 12 point readings were available to us and were assessed in detail. It is clear that in the population under study, irregular opacities were a common occurrence and that their incidence increased with the passing of time. Irregular opacities usually accompanied rounded opacities although they occasionally occurred alone, as the table demonstrates.

Of the 90 miners who had a final $x$-ray before death and also an earlier $x$-ray, $55(61 \%)$ had rounded opacities only at the first examination, whereas at the final $x$-ray examination there were only $36(40 \%)$ such cases. During the same time irregular and mixed opacities increased from $18(20 \%)$ to $40(44 \%)$. Eighteen of the original 55 purely rounded cases acquired irregular opacities, 11 of them reverted to category ' $O$ ', while 26 retained their purely rounded appearances. The mixed and irregular opacities, on the other hand, increased from 18 to 40 mainly at the expense of the rounded opacities, and only one of these reverted to category ' $O$ '. Thus two clearcut events have taken place-irregular opacities have doubled in number and, at the same time, a surprisingly high proportion of the rounded cases appear to have regressed.

The detailed pattern of the type of opacity and their profusion on the final $x$-ray are shown in Tables 2 and 3. It will be seen that the reader recorded a high proportion of the rounded opacities as ' $p$ ' type (46) and that for irregular opacities the fine ' $s$ ' type markings were the most common (41) whereas the ' $u$ ' type were comparatively rare (6).

For each category of the profusion of markings at the final $x$-ray for both rounded and irregular markings, the mean values of the age of the men, of the time since diagnosis, and of the deficit in FEV were calculated and the mean emphysema

TABLE 2

95 Cases of Simple Pneumoconiosis: Radiology at Final X-RAY: CATEgory of Rounded Opacities

\begin{tabular}{c|c|c|c|c|c}
\hline \multirow{2}{*}{$\begin{array}{c}\text { X-ray } \\
\text { category }\end{array}$} & \multicolumn{4}{|c|}{ Rounded opacities } & \multicolumn{1}{c}{ All } \\
\cline { 2 - 5 } cases
\end{tabular}

TABLE 3

95 Cases of Simple Pneumoconiosis: Radiology at Final X-Ray: Category of Irregular Markings

\begin{tabular}{|c|c|c|c|c|c|}
\hline \multirow{2}{*}{$\begin{array}{c}\text { X-ray } \\
\text { category }\end{array}$} & \multicolumn{4}{|c|}{ Irregular markings } & \multirow{2}{*}{$\begin{array}{c}\text { All } \\
\text { cases }\end{array}$} \\
\hline & $0 /-$ & $s$ & $t$ & $u$ & \\
\hline $\begin{array}{l}0 /--0 / 0 \\
0 / 1 \\
1 / 0-1 / 2 \\
2 / 1-2 / 3 \\
3 / 2-3 / 4\end{array}$ & $\begin{array}{r}36 \\
0 \\
0 \\
0 \\
0\end{array}$ & $\begin{array}{r}0 \\
16 \\
16 \\
7 \\
2\end{array}$ & $\begin{array}{l}0 \\
1 \\
3 \\
8 \\
0\end{array}$ & $\begin{array}{l}0 \\
0 \\
1 \\
5 \\
0\end{array}$ & $\begin{array}{r}36 \\
17 \\
20 \\
20 \\
2\end{array}$ \\
\hline All cases & 36 & 41 & 12 & 6 & 95 \\
\hline
\end{tabular}


TABLE 4

95 Cases of Simple Pneumoconiosis: Mean Values at Time of Final X-Ray: Mean Emphysema COUNT POSTMORTEM By CATEgory of ROUNDED Opacities

\begin{tabular}{c|c|c|c|c|c}
\hline $\begin{array}{c}\text { Rounded } \\
\text { opacities } \\
\text { category }\end{array}$ & $\begin{array}{c}\text { Number } \\
\text { of } \\
\text { cases }\end{array}$ & $\begin{array}{c}\text { Mean } \\
\text { age }\end{array}$ & $\begin{array}{c}\text { Mean time } \\
\text { since } \\
\text { diagnosis }\end{array}$ & $\begin{array}{c}\text { Mean } \\
\text { deficit } \\
\text { in FEV }\end{array}$ & $\begin{array}{c}\text { Mean count } \\
\text { of } \\
\text { emphysema }\end{array}$ \\
\hline $0 / 0-0 / 1$ & 24 & 64.6 & $11 \cdot 1$ & $-1 \cdot 11$ & 9.1 \\
$1 / 0-1 / 2$ & 31 & 64.2 & 10.5 & -0.82 & 6.8 \\
$2 / 1-3 / 4$ & 40 & 63.1 & 12.7 & -0.98 & 12.0 \\
\hline All cases & 95 & 63.8 & 11.6 & 9.6 \\
\hline
\end{tabular}

TABLE 5

95 Cases of Simple Pneumoconiosis: Mean Values at Time of Final X-ray: Mean Emphysema COUNT POSTMORTEM By Category of IrRegular Opacities

\begin{tabular}{c|c|c|c|c|c}
\hline $\begin{array}{c}\text { Irregular } \\
\text { opacities } \\
\text { category }\end{array}$ & $\begin{array}{c}\text { Number } \\
\text { of } \\
\text { cases }\end{array}$ & $\begin{array}{c}\text { Mean } \\
\text { age }\end{array}$ & $\begin{array}{c}\text { Mean time } \\
\text { since } \\
\text { diagnosis }\end{array}$ & $\begin{array}{c}\text { Mean } \\
\text { deficit } \\
\text { in FEV }\end{array}$ & $\begin{array}{c}\text { Mean count } \\
\text { of } \\
\text { emphysema }\end{array}$ \\
\hline $0 / 0-0 / 1$ & 53 & 62.1 & 11.6 & -0.89 & $7 \cdot 1$ \\
$1 / 0-1 / 2$ & 20 & 65.9 & 11.4 & -0.94 & -1.25 \\
$2 / 1-3 / 4$ & 22 & 66.1 & 11.8 & -0.98 & 14.4 \\
\hline All cases & 95 & 63.8 & 11.6 & 9.6 \\
\hline
\end{tabular}

count was recorded at the postmortem examination. The results are shown in Tables 4 and 5 and in Figure 1. There was no difference between the ages of the men or in the duration of the disease until death between radiological categories. There was, however, a strong association between the profusion of irregular opacities and both the deficit in FEV and an increased enphysema count. Whereas, in contrast, there was a lack of correlation between the rounded opacities and both deficit in FEV and emphysema count. For the irregular opacities the deficit in FEV increased from $\mathbf{0 . 8 9}$ for category $O$ to 0.94 for category 1 , to 1.25 for categories 2 and 3 , and the emphysema count increased from $7 \cdot 1$ to 10.7 to 14.4 . In contrast, the rounded opacities did not show a regular progression but showed the least pathology in category 1; the deficit in FEV was 1.11 for category $0,0.82$ for category 1 , and 1.04 for categories 2 and 3 ; the emphysema counts were $9 \cdot 1,6 \cdot 8$, and $12 \cdot 0$.

It should be noted that the 10 miners shown in Table 1 with purely irregular opacities at the final $x$-ray would all be included in the category $O$ of rounded opacities and that some of these were suffering from a significant degree of pneumoconiosis. It is apparent, therefore, that if irregular opacities are a true indication of emphysema resulting from pneumoconiosis then no radiological classification which fails to take them into account can be expected to indicate consistently either the full extent of the disease or the disability resulting from it.

\section{Discussion}

It is shown that irregular opacities were commonly present in many of the radiographs in the group under study and also that these opacities became relatively more common with the passing of time. It is acknowledged that the group of miners under study was a selected one in terms of death, disease and age and, therefore, the findings cannot necessarily be directly related to coal miners as a whole. It should also be noted that although there was a wide age scatter, the average miner was aged 53 at the time of diagnosis and 64 at death. Many such cases would, even at the earlier age, have already completed some $\mathbf{4 0}$ years in the coal mining industry and most of those who had remained in it would have moved back from the coal face and would be working in less dusty or dust free jobs.

Since the rounded radiological categories in coalworkers' pneumoconiosis have been shown to be 
related to dust content, (Rossiter 1972), it would seem reasonable not to expect further radiological progression with cessation or decrease of dust exposure and this could account for the lack of progression and regression in some of these cases. On the other hand, the irregular and linear opacities which appear to be related to emphysema and parenchymal change might well be expected to increase with maturation of the disease, particulrly if fibrosis or its precursors are already present even in the absence of further dust exposure, such as is recognized to occur in silicosis and some cases of progressive massive fibrosis.

The radiological regression shown in Table 1 may be due to emphysema.Penman (1971) reported similar findings which he attributed to that cause. It can be argued that the irregular opacities may be due to emphysema associated with smoking or cryptogenic fibrosing alveolitis, superimposed on simple pneumoconiosis, but we believe that the evidence is against this. Virtually all those who have studied the morbid anatomy of coalworkers' pneumoconiosis in detail have noted the presence of emphysema which they attributed to the disease. In addition to Gough (1947) and Heppleston (1947), previously referred to, Jones (1943), Gooding (1946), Ruyssen, Walter, and Lang
(1950), and Duguid and Lambert (1964) have all so reported. More recently, we have shown (Ryder et al., 1970) that the amount of emphysema in a group of miners with simple pneumoconiosis was considerably in excess of that of a contrast population drawn from an area with a high incidence of respiratory disease, and Naeye (1972) has reported similar findings. We are not aware of any good evidence to suggest that all this emphysema is due to the effects of smoking rather than pneumoconiosis although no doubt the former makes a contribution in some cases. Also it is worth noting that 12 cases out of the 95 in this study were lifelong 'non smokers', eight of them showed mixed radiological opacities and four of these had extensive emphysema, a count of 20 or more.

Cryptogenic fibrosing alveolitis is a disease which develops and progresses, comparatively speaking, more rapidly than coalworkers' pneumoconiosis and is usually fairly readily distinguishable from it because of its radiological distribution, physiological profile, and clinical stigmata.

The findings in the group studied also seem to indicate that not only are irregular opacities common in simple coalworkers' pneumoconiosis but also to imply that such changes, whatever their origin may 
be, are a better guide to disablement than purely rounded opacities. It is interesting, for instance, that a relationship between numerical category of simple pneumoconiosis on the onehand and emphysema and impairment of ventilation on the other can be demonstrated if the films are read for irregular opacities only, whereas no such relationship exists if the films are read for rounded opacities only. This certainly offers an explanation as to why many cases of socalled category ' $O$ ' may be substantially disabled, and if it can be shown that these opacities are either directly or indirectly brought about by dust within the lungs, our ideas pertaining to the disease will need to be appropriately adjusted. We have already indicated elsewhere (Lyons et al., 1972) that parenchymal involvement including emphysema and dust impregnated interstitial fibrosis may be responsible for reticular and 'irregular often cystic appearances sometimes present in the $x$-ray film'. The present findings would seem to confirm this, in so far as emphysema is concerned. We also pointed out that in certain cases pathological changes which could equally be described as interstitial fibrosis or emphysema occur. The presence of an interstitial fibrosis in coalworkers might well be expected, as asbestos and kaolin-and occasionally silica-may all induce this pulmonary reaction, and lesions of this nature have been recognized by Seal and Wagner (1973) in the lungs of coalworkers previously classified radiologically as having fine nodular opacities.

In order to study this hypothesis further and to

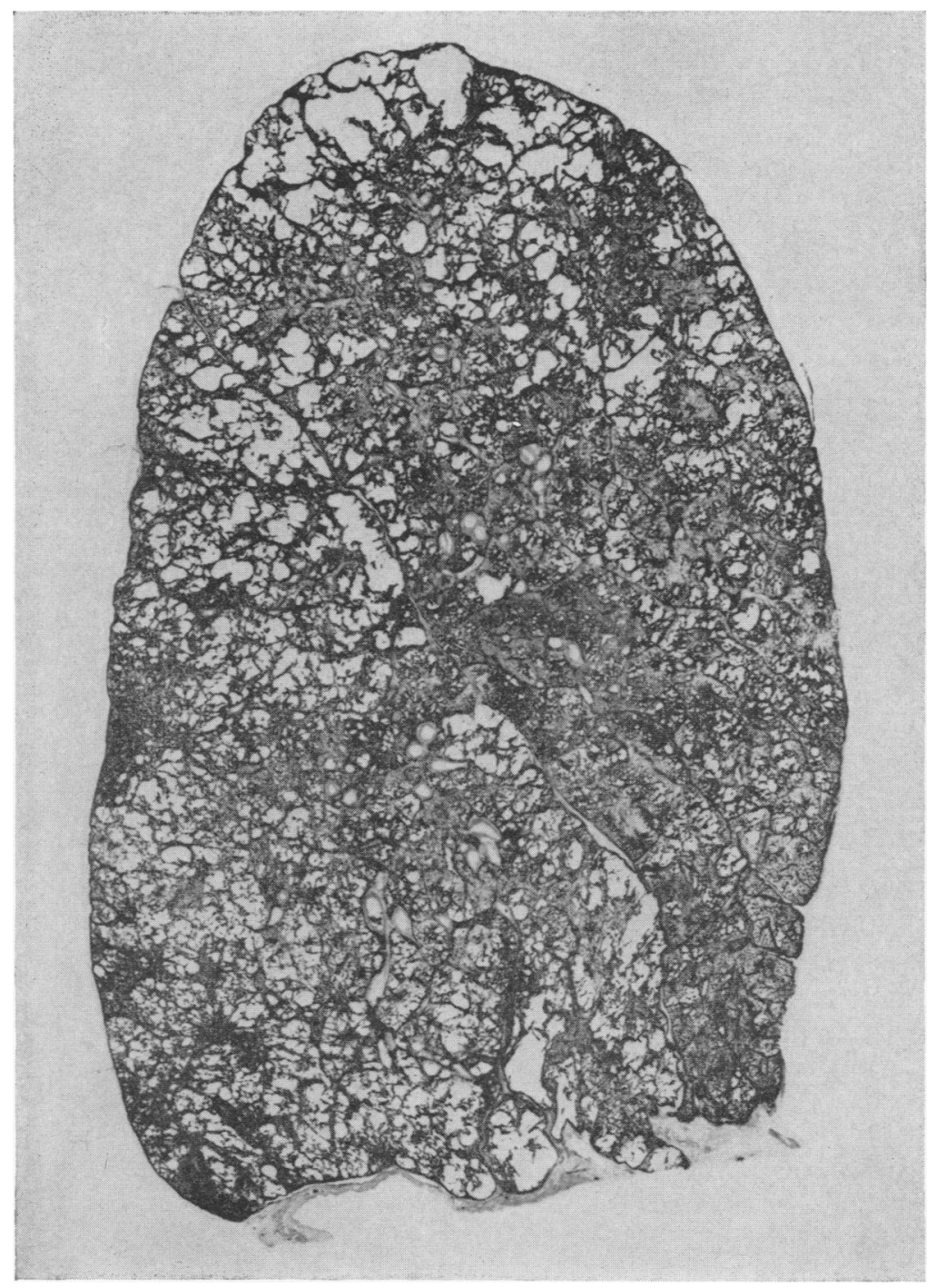

FIG. 2. Whole-lung section from a miner who showed well-marked mixed radiological opacities during life. Categorized p $3 / 2$, s $3 / 2$. 


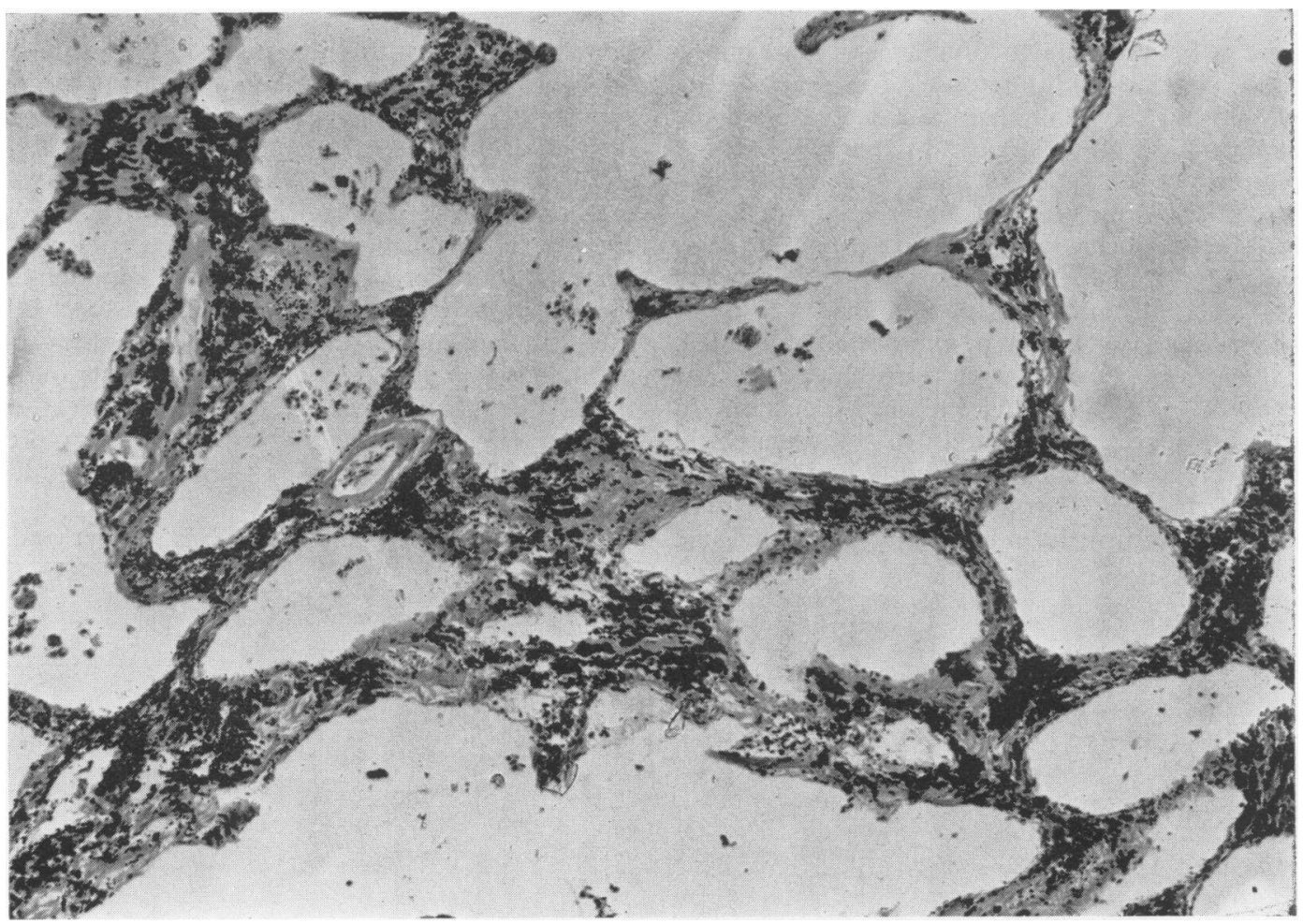

FIG. $3 \mathrm{a}$

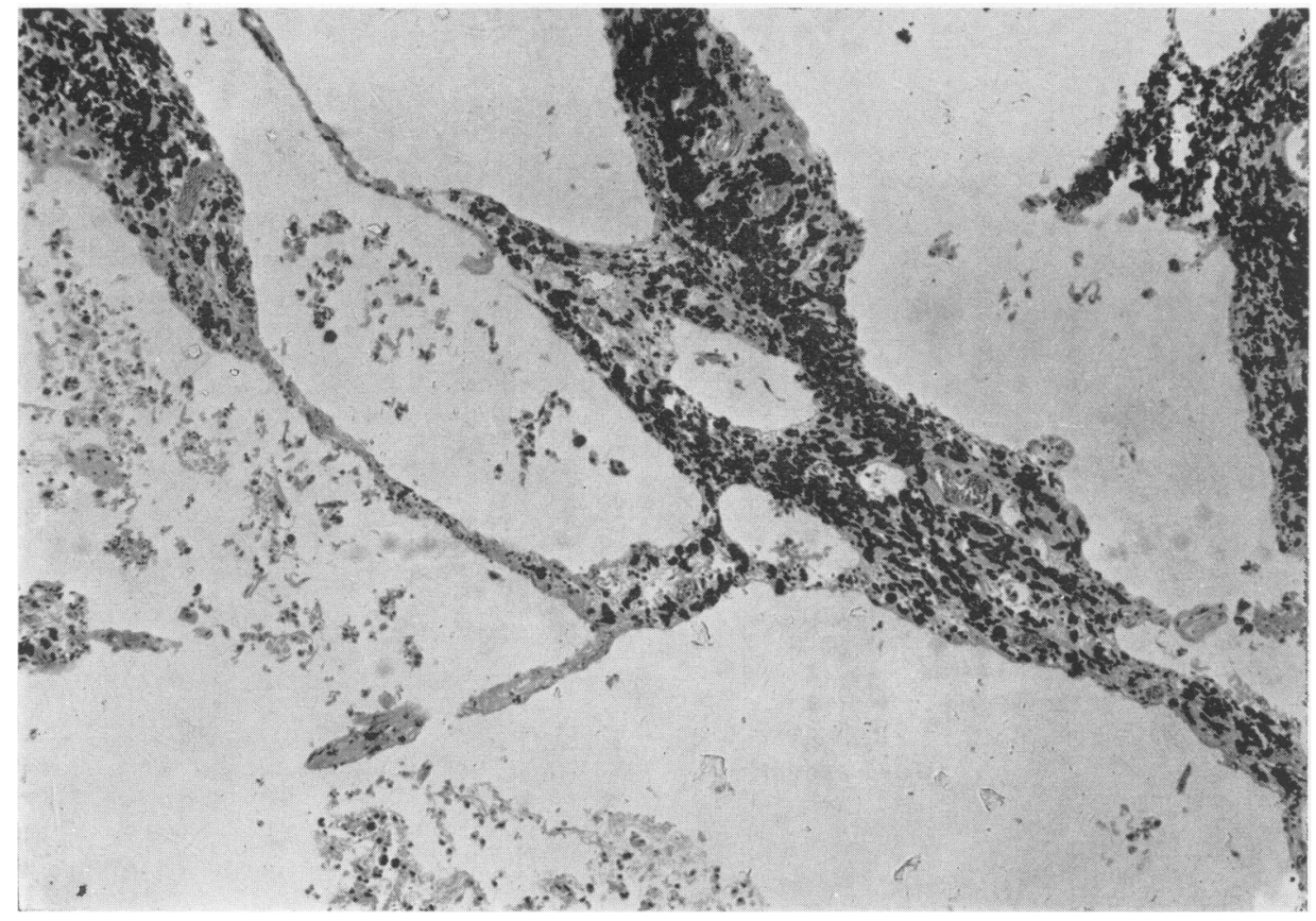

FIG. $3 b$ 


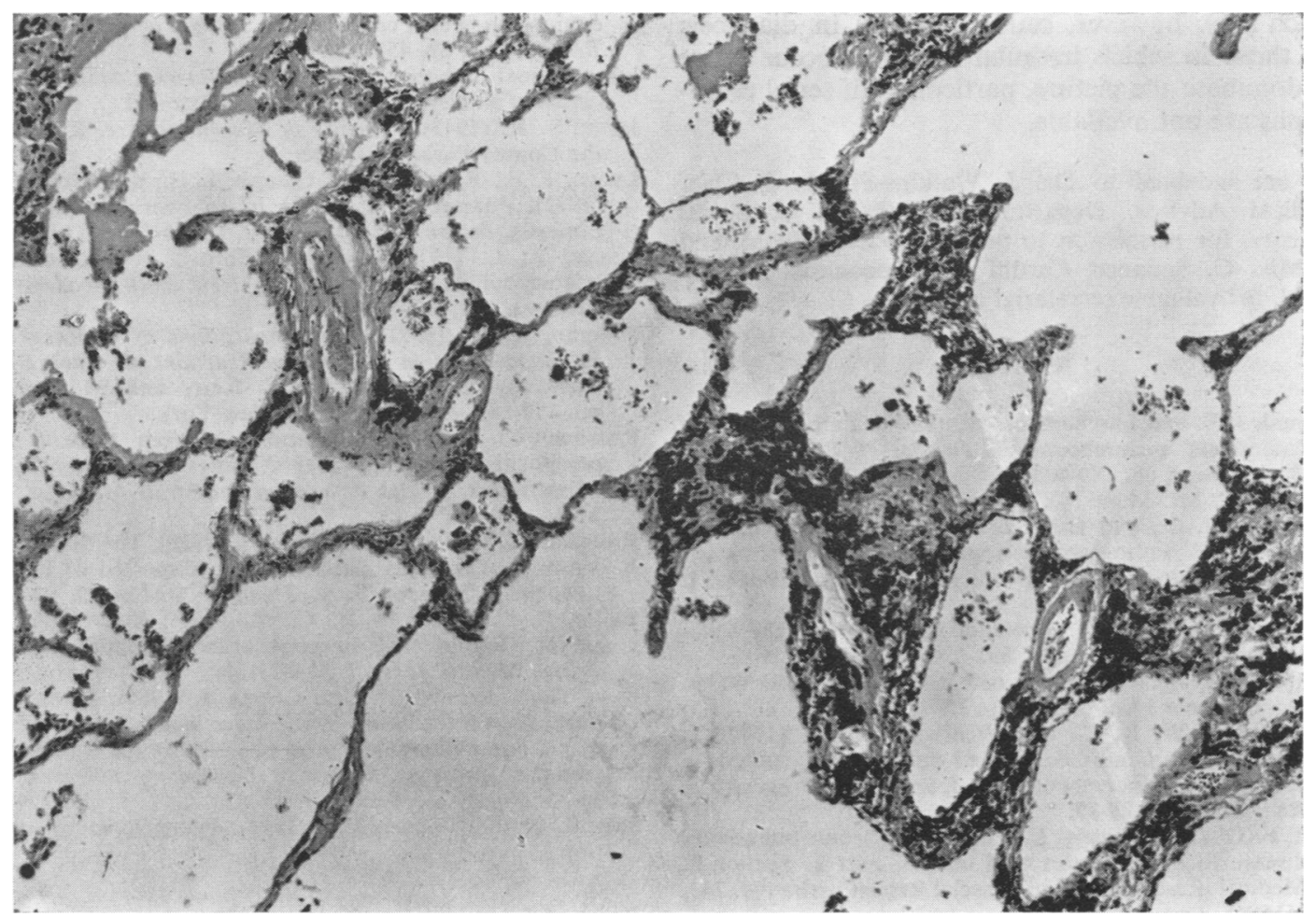

FIG. 3c

FIG. $3(\mathrm{a}, \mathrm{b}, \mathrm{c})$. Microsections $\times 88$ from same case as in Figure 2. Show irregular and linear patterns of fibrosis related to coal dust deposition in the lung parenchyma.

examine in more detail the morbid anatomical findings in the cases showing irregular radiological opacities, specialized study of the material is required and is currently being undertaken. At this stage, in considering only the findings arising from morbid anatomical studies carried out so far, we can only state that the cases with profuse irregular markings radiologically show more parenchymal destruction including emphysema than those with purely rounded opacities. Most cases, however, have pathological features in common, and typical coal nodules were always present even in the ten cases which radiologically showed irregular opacities solely at final $x$-ray. Seven of these showed significant degrees of pneumoconiosis at necropsy.

Figures 2 and 3 demonstrate morbid anatomical material taken from a typical case showing wellmarked mixed opacities, classified ' $p$ ' $3 / 2$, 's' $3 / 2$ at final $x$-ray. It is apparent from them that substantial parenchymal involvement with emphysema and pigmented interstitial fibrosis has taken place. Classical coal dust nodulation, both rounded and stellate, can be seen in the large section together with similar but irregular areas of pigmented fibrosis. It would not seem unreasonable to conclude that these fibrotic changes are responsible for both the rounded and irregular opacities in the radiograph notwithstanding the recognized difficulties of relating specific radiological changes to pathology.

We are not, however, advocating at the present time that irregular opacities should be considered on a par with classical rounded opacities; obviously more investigation needs to be undertaken before their rightful place in the radiology of coalworkers' pneumoconiosis can be established. Their reintroduction into the ILO Classification and their judicious use in coalworkers' pneumoconiosis is, we believe, quite justified since our findings suggest that irregular opacities may be evidence for the occurrence of emphysema and other parenchymal involvement in the evolution of the disease. We are not suggesting either that the presence of irregular markings is likely to cause very much difficulty in the routine diagnosis of coalworkers' pneumoconiosis. They are quite familiar to experienced observers, being usually intimately mixed with rounded opacities, and although their significance may not be uniformly interpreted, the diagnosis is seldom in doubt. Cases 
which may, however, cause difficulty in diagnosis are those in which irregular opacities occur alone or dominate the picture, particularly if serial radiographs are not available.

We are indebted to Dr. J. Watkins-Pitchford, Chief Medical Adviser, Department of Health \& Social Security, for permission to use the Panel material, and to Miss C. Squance, Cardiff Pneumoconiosis Medical Panel, for valuable secretarial assistance.

\section{References}

Duguid, J. B. and Lambert, M. W. (1964). Pathogenesis of coalminers' pneumoconiosis. Journal of Pathology and Bacteriology, 88, 389-403.

Fletcher, C. M., Mann, K. J., Davies, I., Cochrane, A. L., Gilson, J. C., and Hugh Jones, P. (1949). The classification of radiographic appearances in coalminers' pneumoconiosís. Journal of the Faculty of Radiologists, 1 , 40-60.

Gooding, C. G. (1946). Pneumoconiosis in South Wales anthracite miners. Lancet, 891-896.

Gough, J. (1947). Pneumoconiosis in coalworkers in Wales. Occupational Medicine, 4, 86-97.

- James, W. R. L., and Wentworth, J. E. (1949). A comparison of radiological and pathological changes in coalworkers' pneumoconiosis. Journal of the Faculty of Radiologists, 1, 28-39.

Hart, P. D'A. and Aslett , E. A. (1942). Chronic pulmonary disease in South Wales coal miners, part 1. Section B. Medical Research Council Special Report Series No. 243, HMSO, London.

Heppleston, A. G. (1947). The essential lesion of pneumo- coniosis in Welsh coalworkers. Journal of Pathology and Bacteriology, 59, 453-460.

International Labour Office (1970). International Classification of Radiographs of Pneumoconioses. ILO, Geneva.

Jones, S. R. (1943). Silicosis in Monmouthshire. Report of the County Pathologist, Oct. 1.

Lyons, J. P., Ryder, R. C., Campbell, H., and Gough, J. (1972). Pulmonary disability in coalworkers' pneumoconiosis. British Medical Journal, 1, 713-716.

Naeye, R. L. (1972). Types of fibrosis in coalworkers' pneumoconiosis. Annals of the New York Academy of Sciences, 200, 381-399.

Penman, R. W. (1971). In Complications of Coalworkers' Pneumoconiosis in Pulmonary Reactions to Coal Dust, edited by M. M. Key, L. E. Kerr, and M. Bundy, pp. 179-185. Academic Press, New York.

Rossiter, C. E. (1972). Relations between content and composition of coalworkers' lungs and radiological appearances. British Journal of Industrial Medicine, 29, 31-44.

Russyen, L., Walter, L., and Lang, J. (1950). The findings at autopsy of subjects affected by or suspected of having silicosis on 76 cases. Revue Médicale Minière, 3, 93-107.

Ryder, R. C., Lyons, J. P., Campbell, H., and Gough, J. (1970). Emphysema in coalworkers' pneumoconiosis. British Medical Journal, 3, 481-487.

- Thurlbeck, W. M., and Gough, J. (1969). A study of interobserver variation in the assessment of the amount of pulmonary emphysema in paper-mounted whole lung sections. American Review of Respiratory Diseases, 99, 354-364.

Seal, R. E. and Wagner, J. C. (1973). Personal communication.

Received for publication 17 May, 1973.

Accepted for publication 15 September, 1973. 